Jurnal Pendidikan Agama Islam Universitas Wahid Hasyim Semarang

\title{
PENDIDIKAN KARAKTER \\ DALAM LARANGAN MENYEMBELIH SAPI (Menelisik Filosofi Ajaran Sunan Kudus)
}

\author{
Mahlail Syakur Sf. \\ Dosen FAI Universitas Wahid Hasyim Semarang \\ e-mail: syakur@unwahas.ac.id
}

\begin{abstract}
Abstrak
Islam as a part of the social system comes with a mission as rahmah lil- 'alamin to take part in nation-building. On the other sides Indonesia is a multicultural country where Islam is one of the subsystems. Therefore, Islam should be introduced as the potential for an inclusive, democratic and pluralist. Sunan Kudus spreads Islam by way of acculturation traditions and local culture because at that time the majority of the population is Hindu Holy.This research includes the study of literature (library research) using the method of documentation and descriptive. Descriptive method is used to describe all of the information about the fatwa Sunan Kudus and his background. The researcher also used a historical approach to photographing the events of the past time. There are two findings in this study, namely: (1) Prohibition of slaughtering cows that produce discourse that the Kudus people have high awareness for religious tolerance when Islam was come to Kudus, (2) Character education in banning slaughter cows produced a discourse that architecture of Mosque and Kudus Minaret and fatwa "Prohibition of slaughtering cows" contains the educational value of inter-religious tolerance. Methods and strategies of propaganda Sunan Kudus conceived a view to educating the Muslim community in order to have a noble character, are willing to respect and appreciate the confidence the Hindu community who believed that the cow is considered sacred animals.
\end{abstract}

Keywords: character education, slaughtering cows, tolerance

Islam sebagai bagian dari sistem sosial hadir dengan misi sebagai rahmah lil'alamin untuk ambil bagian dalam pembangunan bangsa. Di sisi lain Indonesia merupakan negara multikultural dimana Islam merupakan salah satu subsistemnya. Oleh karena itu, Islam harus diperkenalkan sebagai potensi yang inklusif, demokratis dan pluralis. Sunan Kudus menyebarkan agama Islam melalui akulturasi tradisi dan budaya lokal karena pada saat itu PROGRESS - Volume 9, No. 1, Juni 2021 
Jurnal Pendidikan Agama Islam Universitas Wahid Hasyim Semarang

mayoritas penduduknya beragama Hindu Kudus.Penelitian ini termasuk studi kepustakaan (library research) dengan menggunakan metode dokumentasi dan deskriptif. Metode deskriptif digunakan untuk menggambarkan semua informasi tentang fatwa Sunan Kudus dan latar belakangnya. Peneliti juga menggunakan pendekatan sejarah untuk memotret peristiwa masa lalu. Terdapat dua temuan dalam penelitian ini, yaitu: (1) Larangan penyembelihan sapi yang menghasilkan wacana bahwa masyarakat Kudus memiliki kesadaran toleransi beragama yang tinggi ketika Islam masuk ke Kudus, (2) Pendidikan karakter dalam larangan menyembelih sapi menghasilkan wacana yang Arsitektur Masjid dan Menara Kudus serta fatwa "Larangan menyembelih sapi" mengandung nilai pendidikan toleransi antar umat beragama. Metode dan strategi dakwah Sunan Kudus dikandung pandangan untuk mendidik umat Islam agar berakhlak mulia, mau menghormati dan menghargai kepercayaan masyarakat hindu yang meyakini bahwa sapi dianggap hewan suci.

Kata kunci: pendidikan karakter, menyembelih sapi, tolerans

\section{A. Pendahuluan}

Islam sabagai bagian dari sistem sosial hadir dengan membawa misi rahmah lil-'alamin untuk ambil bagian dalam pembangunan bangsa. Di sisi lain Indonesia merupakan Negara multikultural yang mana Islam merupakan salah satu subsistem. Oleh karena itu, Islam harus diperkenalkan sebagai potensi yang inklusif, demokratis, dan pluralis. Dengan demikian, Islam lebih mudah diterima oleh masyarakat berbasis multikultural seperti di kabupaten Kudus, Indonesia.

Sejak lama masyarakat Kudus terstruktur atas banyak penduduk dan golongan yang memeluk agama berbeda-beda, seperti yang digambarkan Bhineka Tunggal Ika bahwa Negara kita mempunyai agama yang berbeda-beda. Kondisi tersebut mempunyai korelasi positif dengan kondisi umum masyarakat di Jawa pada saat itu yang telah mengenal agama sebelum Islam, yaitu Hindu dan Budha. Kondisi tersebut bukan 
Jurnal Pendidikan Agama Islam Universitas Wahid Hasyim Semarang

merupakan halangan bagi penyebar ajaran Islam di kabupaten Kudus pada masa awal, yaitu Sunan Kudus ${ }^{1}$.

Kemudian sebagaimana dijelaskan oleh Geertz bahwa sebagian besar masyarakat di pulau jawa terbagi dalam tiga golongan; abangan, santri, dan priyayi.2 Golongan ini dikemukakan oleh Greetz karena pengaruh agama Hindu-Budha yang menerapkan kasta dalam ajarannya. Selanjutnya, masyarakat Kudus juga telah mengenal banyak agama yang berkembang meskipun yang memeluk agama Islâm menduduki peringkat teratas. Heterogenitas tersebut berimplikasi pada suburnya adat dan budaya, baik bernuansa lokal, Islâm, maupun lainnya. Struktur masyarakat Kudus yang majmuk, secara otomatis menuntut dan sekaligus menuntun kehidupan masing-masing individu atau golongan agar dapat menerima perbedaan, saling menghormati dan menghargai satu sama lain dalam interkasi dan komunikasi, baik dalam intern ummat beragama maupun antar ummat beragama. Dengan demikian kecerdasan sosial sangat dibutuhkan oleh masing-masing individu. Oleh karena itu, guna mewujudkan kecerdasan sosial maka pendidikan karakter dirasa sangat berarti bagi mereka.

${ }^{1}$ Sunan Kudus adalah salah satu dari komunitas Walisongo. Nama lengkapnya adalah Sayyid Ja'far Shadiq bin Sunan Ngudung bin Fadhal Ali Murtadha bin Ibrahim Zainuddin al-Akbar bin Jamaluddin al-Husain bin Ahmad Jalaluddin bin Abdillah bin Abdul Malik Azmatkhan bin Alwi Ammil Faqih bin Muhammad Shahib Mirbath bin Ali Khali' Qasam bin Alwi bin Muhammad bin Alwi bin Ubaidillah bin Ahmad al-Muhajir bin Isa bin Muhammad bin Ali al-Uraidhi bin Ja'far Shadiq bin Muhammad al-Baqir bin Ali Zainal Abidin bin al-Husain bin Sayyidah Fathimah az-Zahra binti Nabi Muhammad saw. Lihat Azmatkhan, Shohibul Faroji. Ensiklopedi Nasab Imam al-Husain (Penerbit Walisongo Center, 2011), h. 30.

2 Lihat dalam The Religion of java, (London: The Free Press of Glencoe, 1960). Geertz membagi masyarakat Jawa ke dalam tiga varian: Abangan, Santri dan Priyayi. Meski menuai banyak kritik, namun teorinya hamper selalu mewarnai penelitian-penelitian berikutnya, terutama yang serius meneliti tentang kultur Jawa.

PROGRESS - Volume 9, No. 1, Juni 2021 
Jurnal Pendidikan Agama Islam Universitas Wahid Hasyim Semarang

Disisi lain semangat kebersamaan dan kebangsaan merupakan skala prioritas Sunan Kudus dalam setiap langkah perjuangan dan penyebaran agama Islam. Hal tersebut diketahui, masih sulitnya pemisahan agama dari tradisi dan budaya lama. Bahkan Sunan Kudus tidak serta merta menghapus semua adat, budaya, dan tatacara hidup dari agama sebelumnya yang dianut oleh masyarakat Kudus. Lebih dari itu Kanjeng Sunan Kudus mengajarkan kepada masyarakat Muslim agar memiliki karakter yang mulia seperti menghormati dan menghargai perilaku keagamaan golongan lain yang memeluk agama Hindu dengan cara melakukan akulturasi dalam beberapa aspek kehidupan. Hal tersebut dapat diperhatikan simbol-simbol agama Hindu yang ditemukan dalam arsitektur masjid al-Aqsha ${ }^{3}$ dan Menara Kudus ${ }^{4}$.

Selain itu, tidak kalah menarik untuk dikaji adalah fatwanya tentang larangan menyembelih lembu bagi masyarakat Kudus. Fatwa ini merupakan salah satu fenomena sosial keagamaan karena masih ditaati oleh mayoritas masyarakat Kudus sejak sekitar 500 tahun silam yang dipandang sebagai strategi pendidikan karakter bangsa yang sangat efektif pada masanya.

Berdasarkan paparan singkat tersebut maka penilitian ini diangkat berdasarkan masalah apakah hakekat ajaran Sunan Kudus tentang

3 Masjid ini didirikan pada tahun 956 H./ 1549 M. oleh Sayyid Ja'far Shadiq (Sunan Kudus). Pendiriannya dibuktikan dengan prasasti berbahasa Arab. Prasasti berisi empat hal, yaitu tahun pendirian masjid, nama pendiri, nama masjid al-Aqsha, dan daerah di sekitarnya yang sebelumnya bernama Tajug kemudian diperbarui dengan nama Kudus yang berasal dari bahasa Arab al-Quds (suci). Konon, batu prasasti yang saat ini berada di atas mihrab dibawa langsung oleh Sunan Kudus dari Mekkah. Sedangkan keramik hiasannya, menurut arkeolog asal Jepang, Sakai Takashi dan Takimoto Tadashi, adalah buatan pabrik keramik di Vietnam abad ke-14 hingga ke-15 M.

${ }^{4}$ Lihat G.F. Pijper, The Minaret in Java dalam Jean Philippe Vogel, India Antiqua: a Volume of Oriental Studies (Leyden: E.J. Brill, 1947), h. 280.

PROGRESS - Volume 9, No. 1, Juni 2021 
Jurnal Pendidikan Agama Islam Universitas Wahid Hasyim Semarang larangan menyembelih sapi? Dan nilai pendidikan karakter apakah yang terkandung di dalamnya?

\section{B. Kajian Literatur}

Kudus merupakan bagian dari wilayah Majapahit (1293 - 1500 M.), dimana Majapahit adalah kerajaan Hindu terakhir di Jawa. Maka tidak mengherankan jika sebagian besar masyarakat Kudus memeluk agama Hindu dan sebagian lagi memeluk agama Budha. Di sisi lain seorang Muslim keturunan Tiongkok (Cina) bernama The Ling Sing (kemudian dikenal sebagai Kyai Telingsing) telah berpengaruh di Kudus sebelum Sunan Kudus. Kehadiran Sunan Kudus membuat proses penyebaran Islam di kota ini kian melaju sangat cepat dengan menggunakan pendekatan struktural dan cultural sebagai manifestasi pendidikan karakter melalui metode khususnya.

\section{Hakekat Pendidikan Karakter}

Jika memperhatikan konsep pendidikan Paulo Freire bahwa bukan merupakan "menara gading" yang berusaha menjauhi realitas sosial dan budaya, tetapi pendidikan itu harus mampu menciptakan tatanan masyarakat yang terdidik dan berpendidikan, bukan sebuah masyarakat yang hanya mengagungkan suatu kelas sosial sebagai akibat dari kekayaan dan kemakmuran yang diperolehnya, maka pendidikan dapat dipahami sebagai proses penyadaran bagi setiap individu akan status dan peranannya dalam msyarakat. Dalam konteks ini pendidikan karakter mempunyai hasil yang sangat signifikansi bagi masyarakat majmuk.

PROGRESS - Volume 9, No. 1, Juni 2021 
Jurnal Pendidikan Agama Islam Universitas Wahid Hasyim Semarang

Belakangan ini tema "pendidikan karakter" menjadi perhatian berbagai kalangan dan juga Negara. Hal ini dilakukan dalam rangka mempersiapkan generasi yang berkualitas. Bukan sekadar kepentingan individu warga negara melainkan juga untuk warga masyarakat secara keseluruhan.

Secara etimologis, terma "karakter" mempunyai banyak varian definisi. Kata karakter (character) berasal dari bahasa Yunani (Greek) "charassein" bermakna "to engrave" yang juga berarti mengukir, melukis, memahatkan, atau menggoreskan ${ }^{5}$ atau berarti "to mark", yakni menandai dan memfokuskan bagaimana mengaplikasikan nilai kebaikan dalam bentuk tindakan atau tingkah laku. Maka orang yang tidak jujur, kejam, rakus dan perilaku jelek lainnya dikatakan orang berkarakter jelek, sedangkan orang yang perilakunya sesuai dengan kaidah moral disebut dengan berkarakter mulia. Menurut Kamus Besar Bahasa Indonesia, karakter berarti tabiat, sifat-sifat kejiwaan, akhlak atau budi pekerti yang membedakan seseorang dengan yang lain, dan watak. ${ }^{7}$ Karakter identik dengan kepribadian atau akhlak. Kepribadian merupakan ciri atau karakteristik atau sifat khas dari diri seseorang yang bersumber dari bentukan-bentukan yang diterima dari lingkungan, misalnya keluarga pada masa kecil, dan juga bawaan sejak lahir ${ }^{8}$.

\footnotetext{
${ }^{5}$ John M. Echols dan Hassan Shadily, Kamus Inggris Indonesia: An English - Indonesian Dictionary (Jakarta: PT Gramedia (Echols dan shadily, 2005), h. 214.

${ }^{6}$ E. N. Jones, K. Ryan \& K. E. Bohlin, Teachers as Educators of Character: A the Nation's Schools of Education Coming up Short? (Washington, D.C.: Character Education Partnership, 1999), h. 5.

7 Pusat Bahasa Departemen Pendidikan Nasional, Kamus Besar Bahasa Indonesia (Jakarta: Gramedia, 2008), h. 258.

${ }^{8}$ Doni Koesoema A., Pendidikan Karakter: Strategi Mendidik Anak di Zaman Global (Jakarta: PT Grasindo, 2007, 80.
}

PROGRESS - Volume 9, No. 1, Juni 2021 
Jurnal Pendidikan Agama Islam Universitas Wahid Hasyim Semarang

Adapun secara terminologis, terdapat banyak varian definisi karakter. Di antaranya adalah:

a. Karakter adalah spontanitas manusia dalam bersikap, atau perbuatan yang telah menyatu dalam diri manusia, sehingga ketika muncul tidak perlu dipikirkan terlebih dahulu. ${ }^{9}$

b. Menurut Lickona, karakter adalah "A reliable inner disposition to respond to situations in amorally good way." Lickona menambahkan "Character so conceived has three interrelated parts: moral knowing, moral feeling, and moral behavior". ${ }^{10}$

Jadi, karakter itu mengacu kepada serangkaian sikap (attitudes), perilaku (behaviors), motivasi (motivations), dan keterampilan (skills). Dengan kata lain, karakter adalah kepribadian ditinjau dari titik tolak etis atau moral, misalnya kejujuran seseorang, dan biasanya berkaitan dengan sifat-sifat yang relatif tetap.

Adapun yang dimaksud dengan Pendidikan karakter (character education) adalah setiap usaha secara sengaja dari seluruh dimensi kehidupan untuk membantu pembentukan karakter seseorang secara optimal. Pendidikan karakter merupakan salah satu wacana pendidikan yang dianggap mampu memberikan jawaban atas kebuntuan dalam sistem pendidikan.

Sejalan dengan itu, Pendidikan karakter juga diartikan sebagai upaya penanaman kecerdasan dalam berpikir, penghayatan dalam bentuk sikap, dan pengamalan dalam bentuk perilaku yang sesuai dengan nilai-nilai luhur yang menjadi jati dirinya, diwujudkan dalam interaksi dengan Tuhannya, diri

\footnotetext{
${ }^{9}$ Dali Gulo, Kamus Psikologi (Bandung: Penerbit Tonis, 1982), h. 29.

10 Thomas Lickona, Educating for Character: How Our School Can Teach Respect and Responsibility (New York, Toronto, London, Sydney, Aucland: Bantam books, 1991), h. 51. PROGRESS - Volume 9, No. 1, Juni 2021 
Jurnal Pendidikan Agama Islam Universitas Wahid Hasyim Semarang sendiri, masyarakat dan lingkungannya. ${ }^{11}$ Tujuan utamanya adalah untuk mewujudkan karakter mulia dalam bermasyarakat dan berbangsa sebagai ekspressi kecerdasan emosional dan sosial dalam setiap individu.

Terma "pendidikan karakter" digunakan pada tataran deskriptif dan normatif yang menggambarkan isu-isu dan masalah-masalah pendidikan yang berkaitan dengan masyarakat multikultural. Lebih jauh ia juga mencakup pengertian tentang pertimbangan terhadap kebijakan-kebijakan dan strategi-strategi pendidikan dalam masyarakat multikultural. Dalam konteks deskriptif materi (kurikulum) pendidikan multikultural hendaknya mencakup tema-tema seperti toleransi, perbedaan etno-kultural dan agama, bahaya diskriminasi, penyelesaian konflik dan mediasi, HAM, demokrasi dan pluralitas, multikulturalisme, kemanusiaan universal, dan tema-tema lain yang relevan.

Di antara beberapa penelitian tentang pendidikan karakter yang telah berlalu adalah:

1. Early Character Development and Education oleh Marvin W. Berkowitz \& John H. Grych (jurnal Early Education \& Development, Volume 11, Number J, January 2000);

2. Pendidikan untuk Pengembangan Karakter (Telaah terhadap Gagasan Thomas Lickona dalam Educating for Character) oleh Dalmeri (jurnal Al-Ulum, Volume 14 Nomor 1, Juni 2014);

3. Nilai-nilai dan Konsep Pendidikan Multikultural dalam Pendidikan Islâm oleh Ainun Hakiemah (tesis, IAIN Sunan Kalijaga, 2007);

4. Multikulturalisme dalam Perspektif Hadits dan Implikasinya dalam Pendidikan oleh Soir (tesis, IAIN Sunan Kalijaga, 2009)

Dan satu di antara 18 nilai karakter yang baik adalah toleransi (tasamuh) sebagaimana yang dikembangkan di Indonesia belakangan ini. Sikap tasamuh (تسامح) ini terasa sangat besar terhadap pluralisme pemikiran.

11 Zubaedi, Desain Pendidikan Karakter: Konsepsi dan Aplikasinya dalam Lembaga Pendidikan, (Jakarta: Kencana, 2011), h. 17.

PROGRESS - Volume 9, No. 1, Juni 2021 
Jurnal Pendidikan Agama Islam Universitas Wahid Hasyim Semarang

Berbagai pikiran yang tumbuh dalam masyarakat muslim mendapatkan pengakuan yang apressiatif. Keterbukaan yang demikian lebar menjadikan strategi dakwah Sunan Kudus memiliki kemampuan meredam berbagai konflik internal ummat dan antar ummat beragama. Dalam konteks tersebut Sunan Kudus sangat responsif terhadap realitas sosial reliji di Kudus. Tidak hanya inter ummat tetapi juga antar ummat beragama.

Dalam diskursus sosial-budaya Sunan Kudus banyak melakukan toleransi terhadap tradisi-tradisi yang telah berkembang di masyarakat tanpa melibatkan diri dalam substansinya, bahkan tetap berusaha mengarahkannya. Formalisme dalam aspek-aspek kebudayaan dalam strategi dakwah Sunan Kudus tidak memiliki signifikansi yang kuat. Maka tidak mengherankan dalam tradisi kaum Sunni yang dianut oleh mayoritas Muslim Kudus terkesan bernuansa kultur Syi'ah atau bahkan hinduisme. Maka sebagian kelompok muslim mengecamnya sebagai Ahli kurafat, ahli bid'ah, atau kaum Quburiyyun.

Pendidikan Toleransi yang demikian telah memberikan makna khusus dalam konteks dimensi kemanusiaan (basyariyyah) secara lebih luas. Justeru inilah daya tarik Islam bagi ummat dunia. Pluralistiknya pikiran dan sikap hidup masyarakat adalah keniscayaan. Inilah visi rahmah li al-'alamin di bawah prinsip tauhid.

\section{Larangan Menyembelih Lembu}

Dalam Babad Tanah Jawi di informasikan bahwa Sunan Kudus mengajarkan ilmu (tasawwuf) yang bersumber dari Syekh Abdul Qadir. ${ }^{12}$

12 Bruinessen, Martin van. NU: Tradisi, Relasi-Relasi Kuasa, Pencarian Wacana Baru (Yogyakarta: LKiS, 1988), h. 70. Lihat pula Martin van Bruinessen, Kitab Kuning, Pesantren, dan Tarekat: tradisi-tradisi Islam di Indonesia (Bandung: Mizan, 1995), h. 63.

PROGRESS - Volume 9, No. 1, Juni 2021 
Jurnal Pendidikan Agama Islam Universitas Wahid Hasyim Semarang

Dengan berbekal ilmu tasawuf Sunan Kudus sangat piawai memperkenalkan Islam secara inklusif kepada masyarakat Kudus dan sekitarnya yang heterogen dan multikultural.

Dalam upaya tersebut Sunan Kudus sangat peduli terhadap tradisi dan budaya yang telah lama mengakar di masyarakat. Sikapnya ditunjukkan dengan tidak serta merta menghapus semua adat, budaya, dan tatacara hidup dari agama sebelumnya demi syi'ar Islam, akan tetapi justru sikap tersebut yang menjadikan akulturasi dalam beberapa aspek kehidupan. Pendekatan tersebut dapat diperhatikan antara lain melalui simbol-simbol agama Hindu yang ditemukan dalam arsitektur Masjid al-Aqsha Kudus dan Menara Kudus.

Bangunan Menara merupakan bagian khas dari Masjid al-Aqsha Kudus yang statusnya masih diperdebatkan, apakah menara tersebut merupakan peninggalan budaya Hindu atau peninggalan Sunan Kudus. Kiranya alasan kedua lebih kuat di mata masyarakat Kudus daripada anggapan pertama sebab tata letak menara menghadap ke qiblat, sementara candi Hindu lazim menghadap ke gunung. Kecuali itu tidak ditemukan arca pada Menara. Namun yang sulit dipungkiri adalah bahwa Menara Kudus merupakan indikator akulturasi Islam-Hindu atau wujud pengaruh seni budaya pada zaman pra Islam, sebagaimana di diskripsi peneliti dari India, Dr. G.F. Pijper:

.... The Menara of Kudus does not seem to me to be a minaret, but rather a Hindu structure corresponding in style and in purpose to the present, and indeed far less beautiful, gapura of East Java, which in its turn is again related to the kulkul tower of Bali ... ${ }^{13}$

(...Menara Kudus bagiku bukan sekadar menara tetapi merupakan struktur bangunan yang sesuai dengan gaya Hindu dan bertujuan 
Jurnal Pendidikan Agama Islam Universitas Wahid Hasyim Semarang

untuk saat ini, bahkan jauh lebih indah, gapura di Jawa Timur yang erat berhubungan dengan menara Kulkul Bali...)

Arsitektur masjid dan Menara Kudus yang mempunyai kedekatan dengan arsitektur Hindu tersebut dikandung maksud antara lain adalah untuk menunjukkan sikap hormat dan menghargai atas keyakinan ummat Hindu, sekaligus sebagai daya tarik agar Islam lebih mudah dikenal dan diterima.. Di samping melalui masjid dan menara terdapat banyak hal yang dilakukan oleh Kanjeng Sunan Kudus dalam berdakwah menyebarkan ajaran sekaligus edukasi kebangsaan. Di antaranya adalah dengan tidak melarang masyarakat yang mempunyai kebiasaan menabur bunga di perempatan jalan dan samping jalan, yang suka menaruh sesajen di kuburan, yang meminta pertolongan kepada nenek moyang yang telah meninggal, dan lain-lain yang sekira bertentangan dengan syari'at Islam, tetapi mengarahkannya secara bertahap agar sesuai dengan ajaran Islam.

Kecuali itu, dalam kerangka membumikan Islam di Nusantara Sunan Kudus juga berusaha memperkenalkannya secara inklusif dengan menggunakan strategi dakwah yang unik, yaitu dengan fatwa larangan menyembelih lembu (sapi) bagi kaum Muslimin Kudus yang hendak beribadah qurban pada 'Idul Adlha. Padahal bagi masyarakat Kudus terutama ummat Muslim lembu (sapi) merupakan salah satu hewan yang boleh (halal) dimakan dagingnya, dan boleh digunakan untuk sarana ibadah qurban. Sekiranya patut disimak hadits Jabir ra.:

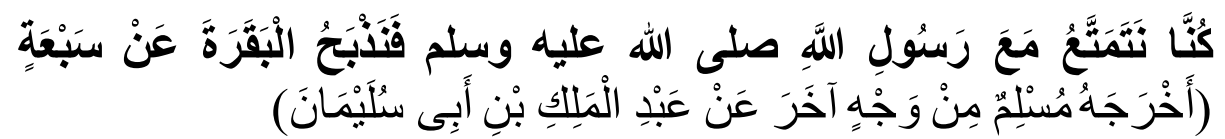

(Kami menunaikan haji dengan cara tamattu' bersama Rasul Allah saw., lalu kami menyembelih lembu untuk tujuh orang). Hadits ditakhrij oleh Imam Muslim 
Jurnal Pendidikan Agama Islam Universitas Wahid Hasyim Semarang

Dengan demikian secara fiqhiyyah, tidak ada larangan bagi mereka untuk menyembelihnya. Akan tetapi bagi masyarakat Muslim di Kudus menyembelih lembu merupakan larangan, bukan karena alasan hukum dengan alasan ta'dhim mengikuti perilaku Kanjeng Sunan Kudus yang tidak berkenan melakukannya ketika itu. Fatwa Sunan Kudus tersebut dilatarbelakangi oleh realitas bahwa mayoritas penduduk Kudus ketika itu adalah penganut Hindu. Dikarenakan menurut Solichin Salam dalam Menara Kudus, sebuah cerita rakyat di Kudus menyebutkan bahwa masyarakat Kudus tidak pernah menyembelih lembu karena dahulu Sunan Kudus pernah merasa dahaga, kemudian ditolong oleh seorang pendeta Hindu dengan diberi air susu sapi. "Maka sebagai rasa terima kasih Sunan Kudus, masyarakat di Kudus dilarang menyembelih binatang sapi," tulis Solichin. ${ }^{14}$ Bagi Umat Hindu lembu diyakini sebagai hewan yang sangat dihormati, dimuliakan. dan disucikan oleh para dewa, sehingga sangat dihormati dan dimuliakan. Maka tujuan utama dikeluarkan fatwa tersebut adalah untuk menghargai kepercayaan agama lain karena saat itu masyarakat Kudus yang memiliki lembu relatif sangat jarang kecuali oleh orang-orang tertentu, yaitu para pemuka agama Hindu.

Realitas tersebut menginisiasi Sunan Kudus untuk mengalihkan perhatian masyarakat dengan cara mengikat seekor lembu "Kebo Gumarang" di halaman masjid ${ }^{15}$. Manakala masyarakat sudah ramai berkumpul di masjid maka Sunan Kudus pun mulai menyampaikan ceramah (mau'idhah hasanah) dengan memberikan uraian tentang surat

${ }^{14}$ Dikutip dari Isnaeni, Hendri F., Toleransi Beragama ala Sunan Kudus, Historia.id/agama.

15 Pada setiap festival Idul Adlha di zaman Sunan Kudus lembu-lembu hanya diikat di sekitar Masjid al-Aqsa Kudus (Masjid Menara), tidak ada yang disembelih untuk qurban. Sebagai gantinya adalah adalah kerbau dan kambing.

PROGRESS - Volume 9, No. 1, Juni 2021 
Jurnal Pendidikan Agama Islam Universitas Wahid Hasyim Semarang

al-Baqarah yang berarti "sapi betina". Dengan cara tersebut masyarakat Hindu tidak merasa terhina oleh sikap pemeluk agama lain, tetapi sebaliknya justeru merasa dihargai kepercayaannya.

Demi penciptaan suasana kebangsaan yang kondusif, rukun dan damai, Sunan Kudus juga mendidik karakter rakyat dengan cara menggubah cerita-cerita ketauhidan, sebuah pendekatan yang kiranya mengadopsi Cerita 1001 Malam. Cerita-cerita/ dongeng disusun secara berseri, sehingga masyarakat tertarik untuk mengikuti seri-seri berikutnya. Ketika menyimak cerita-ceritanya masyarakat menjadi kian terpesona dan terpikat sehingga Sunan Kudus pernah dinilai oleh masyarakat Hindu sebagai Titisan Dewa Wisnu. ${ }^{16}$

Dua pendekatan Sunan Kudus itu terbukti sangat efektif bagi pendidikan karakter bangsa, sehingga masyarakat -tidak terkecuali warga Hindu-- pun berbondong-bondong datang ke masjid guna menyaksikan lembu meskipun awalnya hanya bertujuan untuk menghampiri hewan langka tersebut sambil mendengarkan cerita. Bahkan tidak sedikit di antara mereka yang akhirnya berkonversi dan memeluk Islam. ${ }^{17}$

Pelarangan Menyembelih Lembu bagi masyarakat Kudus merupakan tema yang cukup menarik bagi dunia akademik terutama ditinjau dari aspek sosial keagamaan, namun masih sedikit orang yang menjadikannya sebagai obyek penelitian. Tulisan tentang tema ini masih belum banyak dijumpai melalui penelitian dengan metodolgi yang baku terutama untuk menelisik makna edukatif bagi masyarakat majmuk yang terkandung di dalamnya.

${ }^{16}$ Darmawijaya, Nikmatnya Tasawwuf(Makassar: Pustaka Refleksi, 2008), h. 25.

${ }^{17}$ Ibid.

PROGRESS - Volume 9, No. 1, Juni 2021 
Jurnal Pendidikan Agama Islam Universitas Wahid Hasyim Semarang

Penelitian terhadap pendidikan karakter bidang toleransi terutama pada ranah Islâm Nusantara juga belum mencapai titik final, yakni masih berkutat pada tataran paradigmatik, sebatas konsepsi dan penelusuran nilai-nilai pendidikan Islâm yang relevan dengan pendidikan multikultural ataupun pendidikan karakter.

Studi tentang dakwah Walisongo cukup banyak dilakukan. Di antaranya adalah oleh beberapa peneliti dari Belanda seperti Dr. Bjo Schrieke, Dr. Jgh Gunning, dan Dr. Da Rinkers. Akan tetapi belum ada yang meneliti secara khusus tentang pendidikan karakter dalam fatwanya "larangan menyembeli lembu".

\section{E. Metode Penelitian}

Penelititan ini termasuk jenis penelitian literatur (library research) dengan menggunkan metode dokumentasi dan deskriptif. Bahan dokumentasi yang menjadi rujukan dalam penelitian ini tidak sekadar berupa buku-buku melainkan juga berupa sumber lain yang relevan. Titik tekan penelitian ini adalah informasi tentang teori, dalail, prinsip, pendapat, gagasan, dan lainnya yang dapat digunakan untuk menganalisis dan memecahkan masalah. Metode deskriptif digunakan untuk menjelaskan semua informasi tentang fatwa Sunan Kudus dan latarbelakangnya.

Penelitian ini menggunakan pendekatan kualitatif, yakni prosedur penelitian yang menghasilkan data deskriptif berupa kata-kata tertulis atau 
Jurnal Pendidikan Agama Islam Universitas Wahid Hasyim Semarang

lisan dari orang-orang dan pelaku yang dapat diamati, ${ }^{18}$ baik langsung maupun tidak, atau upaya penggambaran keadaan secara naratif kualitatif. ${ }^{19}$ Penelitian ini juga menggunakan pendekatan Irenic, yaitu usaha untuk membuat jembatan antara cara pandang kelompok terdahulu (Hindu dan Budha) dan para pengikut Islam yang merasa lebih benar sehingga diketahui tujuan untuk memberikan apresiasi yang baik terhadap keberagamaan Islam dan membantu mengembangkan sikap apresiatif itu bagi pihak lain. Langkah ini dilakukan untuk menghilangkan prasangka, perlawanan, dan hinaan. Oleh karena itu, langkah praktis yang dilakukan adalah membangun dialog antara umat Islam dengan warga Hindu di Kudus untuk membangun jembatan penghubung yang saling menguntungkan antara tradisi kegamaan dan bangsa.

Peneliti juga menggunakan pendekatan historis, yakni upaya memotret peristiwa-peristiwa masa lamapau yang dialami oleh manusia, disusun secara ilmiah, meliputi kurun waktu tertentu, diberi tafsiran, dan dianalisis secara kritis sehingga mudah dimengerti dan memiliki manfaat. Menurut Yatimin, fungsi pendekatan ini adalah untuk merekonstruksi masa lampau secara sistematis dan objektif dengan cara mengumpulkan, mengevaluasi, memverifikasi, dan mensistematisasikan bukti-bukti untuk menegakkan fakta dan memperoleh simpulan yang kuat. ${ }^{20}$ Pengumpulan data dilakukan dengan kajian dokumentasi atau literatur dan triangulasi. Sedangkan analisis dilakukan sejak pengumpulan data, reduksi data, penyajian data, dan pengambilan simpulan.

${ }^{18}$ L. Moleong, Metode Penelitian Kualitatif(Bandung: Rosdakarya, 2001), h. 3.

${ }^{19}$ Sukmadinata, Metode Penelitian Pendidikan (Bandung: Rosdakarya, 2005), h. 18.

${ }^{20}$ Bustaman Ahmad Kamaruzzaman, Islam Historis: Dinamika Studi Islam di Indonesia, (Yogyakarta: Galang Press, 2002), h. 7.

PROGRESS - Volume 9, No. 1, Juni 2021 
Jurnal Pendidikan Agama Islam Universitas Wahid Hasyim Semarang

\section{F. Hasil Penelitian dan Pembahasan}

Ada dua hal yang penting untuk disajikan, yaitu:

\section{Larangan menyembelih lembu}

Salah satu ajaran Sunan Kudus yang berkesan di relung relijiusitas masyarakat Kudus adalah "larangan menyembelih lembu". Ajaran tersebut dikemas dalam fatwa keagamaan yang rapi guna mengeliminir gesekan-gesekan psikologis masyarakat Kudus yang majmuk (multicultural). Sikap dan langkah Sunan Kudus tersebut dilatarbelakangi oleh pengetahuan dan kesadaran bahwa jauh sebelum Islam datang kota Kudus merupakan bagian dari wilayah Majapahit yang berpusat di Jawa Timur. Maka tidak mengherankan jika sebagian besar masyarakat Kudus memeluk agama Hindu dan sebagian lagi memeluk agama Budha. Umat Hindu meyakini sapi sebagai hewan yang disucikan oleh para dewa. Jadi, Sunan Kudus mengeluarkan fatwa tersebut guna menghargai kepercayaan agama lain.Fatwa "larangan menyembelih lembu" tersebut menjadi kepercayaan dan masih dipegang teguh oleh masyarakat di Kudus dan sekitarnya hingga kini, bahkan sejumlah perusahaan dan instansi pemerintahan juga menghindari menyembelih sapi di Kudus ${ }^{21}$, dan hanya sedikit dari mereka yang enggan menghormati larangan tersebut dan mengikutinya dengan alasan bid'ah.

Masyarakat Kudus mempunyai kesadaran tinggi untuk menjunjung toleransi beragama manakala Islam hadir di Kudus. Indikatornya adalah keberadaan sebuah klenteng Hok Ling Bio yang

${ }^{21} \mathrm{http}: / /$ www.nakhodaku.com/2015/09/larangan-menye mbelih-sapi-qurban.

PROGRESS - Volume 9, No. 1, Juni 2021 
Jurnal Pendidikan Agama Islam Universitas Wahid Hasyim Semarang

berdiri tidak jauh dari Masjid Menara (al-Aqsha) Kudus dan terlihat pada bangunan Menara Kudus yang merupakan wujud akulturasi dari perpaduan antara Islam, Hindu, dan Budha.

Dengan kesadaran atas realitas sosial tersebut Sunan Kudus segera mengambil inisiatif untuk menciptakan suasana masyarakat yang kondusif guna memperkenalkan Islam di Kudus dengan mengusung tema "pendidikan toleransi'. Tujuan utamanya adalah menjaga dan melestarikan perilaku setiap individu dengan menjunjung tinggi toleransi beragama yang telah ada sebelumnya. Dengan strategi pendidikan karakter berbasis toleransi (tasamuh) tersebut dakwah islamiyyah yang dilakukan oleh Sunan Kudus menuai hasil yang maksimal, baik secara kwantitas maupun kualitas.

\section{Pendidikan Karakter dalam Pelarangan Menyembelih Sapi}

Meski dalam Islam menyembelih sapi adalah hal yang dihalalkan, tetapi untuk menghormati warga Hindu yang tinggal di Kota Kudus saat itu, Sunan Kudus melarang masyarakat Kudus menyembelih sapi. Dengan metode dakwah seperti itu, agama Islam dapat diterima oleh sebagian besar masyarakat Kudus. Warga Hindu pun tidak merasa terhina dan tetap dihargai kepercayaannya. Hal ini membuktikan bahwa Sunan Kudus lebih mengedapankan toleransi dan harmoni daripada konflik dalam memperkenalkan Islam. Keindahan Masjid dan Menara Kudus serta fatwa "larangan menyembelih lembu" mengandung pendidikan toleransi antar umat beragama. Perbedaan agama bukanlah alasan untuk saling menonjolkan ajaran maupun menyombongkan panutan. Sebaliknya, menciptakn suasana indah dan mesra dalam kehidupan multikultural 
Jurnal Pendidikan Agama Islam Universitas Wahid Hasyim Semarang

harus memperoleh perhatian bagi setiap warga. Jika dicermati maka strategi Sunan Kudus menyebarkan agama Islam dengan melarang ummat Islam menyembelih lembu untuk qurban adalah jalan kebijaksanaan ( $b i$ al-hikmah), yakni dengan memperhatikan realitas kehidupan beragama. Strategi inilah yang diperintahkan oleh alQur`an sebelum menggunakan metode lainnya:

(Serulah (manusia) kepada jalan Tuhan-mu dengan hikmah dan pelajaran yang baik, dan bantahlah mereka dengan cara yang baik ...)

Dan sebaliknya, beliau tidak menggunakan cara kekerasan atau paksaan, karena cara ini mengindikasikan selemah-lemah iman seseorang sebagaimana tersirat dalam hadits:

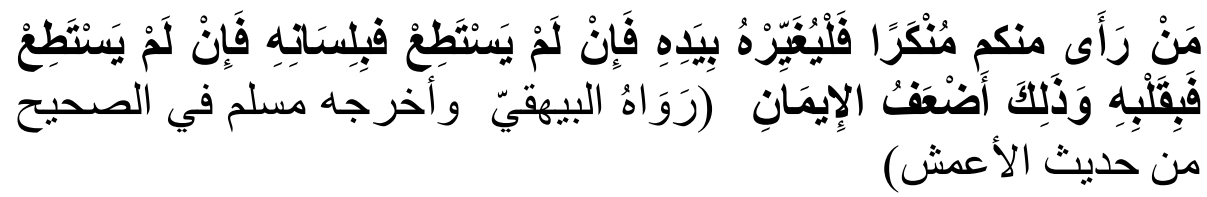

(Siapa pun yang melihat kemunkaran lalu mampu merubahnya dengan tangan maka hendaklah melakukannya, jika tidak mampu maka dengan lisannya, jika tidak mampu maka dengan hatinya. Itulah iman terlemah). HR al-Baihaqi dan ditakhrij oleh Imam Muslim dalam Shahihnya bersumber dari al-A'masy

Dakwah beliau dengan mengedepankan toleransi tersebut laik mendapat simpati dari penduduk yang saat itu masih memeluk agama Hindu, bahkan tidak sedikit di antara mereka memeluk Islam.

\section{G. Simpulan}

Interaksi dan komunikasi dalam masyarakat majmuk (plural sociaty) menuntut setiap individu untuk menyadari posisinya masingmasing dengan tetap menjalankan nilai-nilai agama masing-masing tanpa merusak persatuan dan kesatuan bangsa. Masing-masing individu maupun 
Jurnal Pendidikan Agama Islam Universitas Wahid Hasyim Semarang kelompok harus memiliki sikap empati dan simpati sehingga muncul sikap saling menghormati dan menghargai. Maka diperlukan pendidikan yang mengacu kepada prinsip-prinsip heteroginitas dan nilai-nilai multikultural. Dalam konteks penciptaan suasana kehidupan masyarakat multikultural tersebut Sunan Kudus tampil menjadi guru yang berperan memberikan pendidikan karakter kepada masyarakat Kudus terutama kaum muslimin dengan mengeluarkan fatwa "larangan menyembelih lembu".

Metode dan strategi dakwah Sunan Kudus tersebut dikandung maksud untuk mendidik masyarakat Muslim agar memiliki karakter yang mulia, yaitu sudi menghormati dan menghargai keyakinan ummat Hindu yang berkeyakinan bahwa sapi merupakan hewan yang dianggap suci. Jadi, larangan menyembelih sapi merupakan media pendidikan karakter yang efektif bagi masyarakat Kudus yang majmuk dengan tujuan untuk menanamkan nilai-nilai karakter yang mulia berupa sikap toleransi di kalangan masyarakat, prilaku saling menghargai dan saling menghormati antar ummat beragama. Dengan toleransi suasana indah dan mesra dalam beragama menajdikan nikmatnya berbangsa, dan bernegara sebagaimana telah menjadi tradisi bagi kaum nahdliyyin. 
Jurnal Pendidikan Agama Islam Universitas Wahid Hasyim Semarang

\section{Daftar Pustaka}

Abdullah, Amin. Studi Agama: Normativitas atau Historisitas. Yogyakarta:Pustaka Pelajar, 1999.

Abdullah, Taufik dan M Rusli Karim (ed.), Metodologi Penelitian Agama Sebuah Pengantar, Cet. ke-2, Yogyakarta: Tiara Wacana Yogyakarta, 1990.

Abdullah, Taufik, Sejarah dan Masyarakat, Jakarta: Pustaka Firdaus, 1987.

Ali, M. Sayuthi. Metodologi Penelitian Agama; Pendekatan Teori dan Praktek. Jakarta; RajaGrafindo Persada, 2002.

Badri Yatim, Historiografi Islam, Jakarta:Logos Wacana Ilmu, 1997.

Bruinessen, Martin van. Kitab Kuning, Pesantren, dan Tarekat: tradisi-tradisi Islam di Indonesia. Bandung: Mizan, 1995. Baru. Yogyakarta: LKiS, 1988.

Bustaman, Ahmad Kamaruzzaman. Islam Historis: Dinamika Studi Islam di Indonesia. Yogyakarta: Galang press, 2002.

Darmawijaya. Nikmatnya Tasawwuf, Makassar: Pustaka Refleksi, 2008.

Departemen Pendidikan Nasional. Kamus Besar Bahasa Indonesia. Jakarta: Balai Pustaka, 2003.

Echols, John M. dan Hassan Shadily. Kamus Inggris Indonesia: An English Indonesian Dictionary. Jakarta: PT Gramedia, 2005.

Fay, Brian. Contemporary Philosophy of Social Sience: A Multicultural Approach. Oxrofd: Backwell, 1996.

Fatah, Nur Arifin. Metode Da'wah Walisongo. Bahagia, 1994.

Freire, Paulo. Pendidikan Pembebasan. Jakarta:LP3S, 2000.

Gulo, Dali. Kamus Psikologi. Bandung: Penerbit Tonis, 1982.

Hernandez, Hilda. 2002. Multicultural Education: A Teacher Guide to Linking Context, Process, and Content. New Jersey \& Ohio: Prentice Hall.

http://www.biografiku.com/2010/04/biografi-sunan-kudus.html.

http://www.nakhodaku.com/2015/09/larangan-menyembe lih-sapi-qurban.

PROGRESS - Volume 9, No. 1, Juni 2021 
Jurnal Pendidikan Agama Islam Universitas Wahid Hasyim Semarang

Jones, E. N., Ryan, K. \& Bohlin, K. E., Teachers as educators of character: Are the Nations Schools of Education Coming up Short?. Washington, D.C.: Character Education Partnership, 1999.

Koesoema A., Doni. Pendidikan Karakter: Strategi Mendidik Anak di Zaman Global. Jakarta:PT Grasindo, 2007.

Lickona, Thomas. Educating for Character: How Our School Can Teach Respect and Responsibility, New York, Toronto, London, Sydney, Aucland: Bantam books, 1991.

Martin, Richard. C., Pendekatan Kajian Islam dalam Studi Islam, Surakarta: Muhammadiyah University Press, 2002.

Moleong, L. Metode Penelitian Kualitatif. Bandung: Rosdakarya, 2001.

Muhadjir, Noeng. Metodologi Penelitian Kualitatif: Pendekatan Positivistik, Phenomenologik, dan Realisme Metaphisik, Telaah Studi Teks dan Penelitian Agama, Yogyakarta: Rake Sarasin, 1998.

Nasution, Harun. Tradisi Baru Penelitian Agama Islam Tinjauan Antardisiplin Ilmu, Bandung: Purjalit dan Nuansa, 1998.

Vogel, Jean Philippe. India Antiqua: a Volume of Oriental Studies. Leyden: E.J. Brill, 1947.

Yatim, Badri. Historiografi Islam. Jakarta:PT. Logos Wacana Ilmu, 1997.

Yatimin, M., Abdullah. Studi Islam Kontemporer. Jakarta:Sinar Grafika Offset, 2006.

Zubaedi. Desain Pendidikan Karakter: Konsepsi dan Aplikasinya dalam Lembaga Pendidikan. Jakarta: Kencana, 2011. 